\title{
A Cascaded H-Bridge Multilevel Inverter with SOC Battery Balancing
}

\author{
Khalili Tajeddine, Raihani Abdelhadi, Bouattane Omar, Ouajji Hassan \\ SSDIA Lab, ENSET Mohammedia \\ HASSAN II University \\ Casablanca, Morocco
}

\begin{abstract}
In this paper, we present a single phase 5 levels $\mathbf{H}$ Bridge multilevel inverter (CHMLI) with battery balancing technique. Each single full bridge is directly connected to a battery inside the power bank. The different combinations and batteries wiring sets offer the possibility to control the batteries discharge. The cascaded $\mathbf{H}$-Bridge multilevel inverter is first described and the discharge is studied in normal conditions under different stress scenarios. State of charge (SOC) balancing technique is then achieved using an equalization algorithm controlling the different switching combination inside the power bank. Results of the simulation model with and without the SOC balancing is presented using Matlab.
\end{abstract}

Keywords-Cascaded H-Bridge; multilevel inverter; battery discharge; SOC balancing

\section{INTRODUCTION}

Multilevel inverters today are widely used in renewable energy applications due to their compact architecture and efficient integration. There is three principal types of multilevel inverters: the flying capacitor multilevel inverter (FCMLI), the diode clamped multilevel inverter (DCMLI) and the cascaded H-bridge multilevel inverter (CHMLI) [1]. The CHMLI has proven to be the most reliable type of multilevel inverters [2], [3]. This topology is modular; doesn't require any special modification in case of level change, and is very promising in case of high voltage levels. The CHMLI requires less components than the FCMLI and the DCMLI for the same level. The switches in the CHMLI support the same voltage stress. This multilevel inverter can use directly DC sources to generate staircase voltage levels and continue to operate even when a full bridge is shutdown [4]-[7]. The cascaded H-Bridge multilevel inverter is frequently studied for command improvement involving synchronization strategy and output voltage power levels enhancement [8]-[9]. The CHMLI is very adaptive to photovoltaic systems applications because of its dispatching capability [10]. Due to the importance of levels harmonization in the voltage output many studies have concentrated their efforts on DC power and voltage balance control [11], [12].The control technique in the case of power bank use, relies on the state of charge balancing of DC power storage units (lead acid batteries, capacitors, etc.) [13]-[15]. In this article we present a 5 level $\mathrm{H}$-Bridge multilevel inverter. The functionalities and configuration of the adopted 5 levels CHMLI model is first described. The article then studies the unbalancing voltage impact on this multilevel inverter. We present afterwards a simple technique for batteries balancing using a uniform discharging approach. We used a Matlab
Simulink model to implement the algorithm used to balance the power bank. The final part presents an assessment and analysis of the obtained results.

\section{CASCADED H-BRIDGE MULTILEVEL INVERTER}

\section{A. Generalities on the CHMLI}

The Cascaded H-Bridge Multi-Level Inverter commonly referred to as CHMLI, is an inverter that produces a stair wave voltage output from a multitude of DC sources. The CHMLI uses a combination of full bridge inverters driven by a central command. Fig. 1 presents the architecture of a 5 levels CHMLI multilevel inverter.

The cascaded H-Bridge multilevel inverter is generally used within applications requiring the control of variable speed drives and high voltage delivery. It has a modular structure and a compact design compared to the rest of multilevel inverters. It doesn't require any special alternative in the command law if more levels need to be added which make it a perfect choice for DC-AC conversion application.

Each full bridge converter may generate for itself three possible voltage levels $0,+V_{D C}$ and $-V_{D C}$ where $V_{D C}$ is the nominal voltage of the battery attached to the full bridge section. By combining the different outputs of the full bridge section the CHMLI produces the intended stair wave. With two full bridges the CHMLI produces 5 levels staircase voltage output; generally if $m$ is the number of levels, $N_{s}$ the number independent DC sources and $l$ the number of semiconductor switching components, we obtain the following equations:

$$
\begin{aligned}
& m=2 N_{s}+1 \\
& l=2(m-1)
\end{aligned}
$$

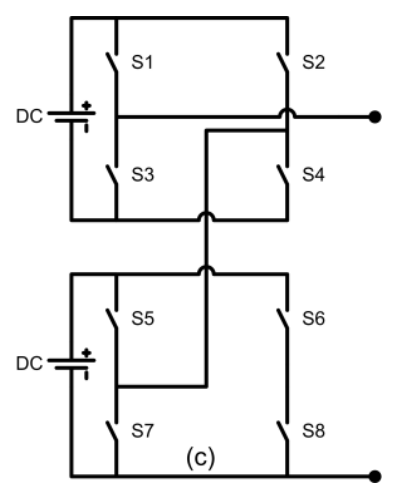

Fig. 1. A five levels CHMLI architecture. 
TABLE I. SWITChing STATE COMBINATIONS 5 LEVELS INVERTER

\begin{tabular}{|c|c|c|c|c|c|c|c|c|}
\hline \multicolumn{7}{|c|}{ Switching Combination State } & Voltage Output \\
\hline $\boldsymbol{S}_{\mathbf{1}}$ & $\boldsymbol{S}_{\mathbf{2}}$ & $\boldsymbol{S}_{\mathbf{3}}$ & $\boldsymbol{S}_{\mathbf{4}}$ & $\boldsymbol{S}_{\mathbf{5}}$ & $\boldsymbol{S}_{\mathbf{6}}$ & $\boldsymbol{S}_{\mathbf{7}}$ & $\boldsymbol{S}_{\mathbf{8}}$ & $\boldsymbol{V}$ \\
\hline 1 & 0 & 1 & 0 & 0 & 1 & 0 & 1 & $2 V_{D C}$ \\
\hline 1 & 1 & 1 & 0 & 0 & 0 & 0 & 1 & $V_{D C}$ \\
\hline 1 & 0 & 0 & 0 & 0 & 1 & 1 & 1 & $V_{D C}$ \\
\hline 1 & 0 & 1 & 1 & 0 & 1 & 0 & 0 & $V_{D C}$ \\
\hline 0 & 0 & 1 & 0 & 1 & 1 & 0 & 1 & $V_{D C}$ \\
\hline 1 & 1 & 1 & 1 & 0 & 0 & 0 & 0 & 0 \\
\hline 1 & 1 & 0 & 0 & 0 & 0 & 1 & 1 & 0 \\
\hline 1 & 0 & 0 & 1 & 0 & 1 & 1 & 0 & 0 \\
\hline 0 & 1 & 1 & 0 & 1 & 0 & 0 & 1 & 0 \\
\hline 0 & 0 & 1 & 1 & 1 & 1 & 0 & 0 & 0 \\
\hline 0 & 0 & 0 & 0 & 1 & 1 & 1 & 1 & 0 \\
\hline 0 & 1 & 1 & 1 & 1 & 0 & 0 & 0 & $-V_{D C}$ \\
\hline 0 & 0 & 0 & 1 & 1 & 1 & 1 & 0 & $-V_{D C}$ \\
\hline 0 & 1 & 0 & 0 & 1 & 0 & 1 & 1 & $-V_{D C}$ \\
\hline 1 & 1 & 0 & 1 & 0 & 0 & 1 & 0 & $-V_{D C}$ \\
\hline 0 & 1 & 0 & 1 & 1 & 0 & 1 & 0 & $-2 V_{D C}$ \\
\hline
\end{tabular}

To understand more accurately the functioning of the five levels CHMLI, we present in Table I, an illustration of all the possible switching combinations. As noticed in Table $\mathrm{I}+V_{D C}$, $-V_{D C}$ and 0 have more than one possible combination sets of switching. This important feature is very useful in case of multi batteries control.

\section{B. The 5 Levels Cascaded H-Bridge Multilevel Inverter Model}

The CHMLI studied in this section and the SOC balancing part is a five level with PWM law command. The law command used for the simulation is a pulse width modulation (SPWM). This method is widely used in multilevel conversion field and consist in comparing the matching reference signal
$\left(V_{\text {ref }}\right)$ to the appropriate number of signal carriers. In the case of 5 levels inverter 4 saw tooth carriers are used. Fig. 2 illustrates the reference signal with the four saw tooth carriers.

The reference signals for a three phased cascaded H-Bridge multilevel inverter can be expressed as follows:

$$
\begin{aligned}
& V_{1 \text { ref }}=A \cdot m \cdot \sin (w t) \\
& V_{2 r e f}=A \cdot m \cdot \sin \left(w t-\frac{2 \pi}{3}\right) \\
& V_{3 r e f}=A \cdot m \cdot \sin \left(w t-\frac{4 \pi}{3}\right)
\end{aligned}
$$

Where:

$A=10$ is the magnitude.

$m=0.6$ is the modulation index.

$A=10$ is the frequency.

Fig. 3 presents the prototype implemented on Matlab Simulink to assess the functioning of the studied CHMLI.

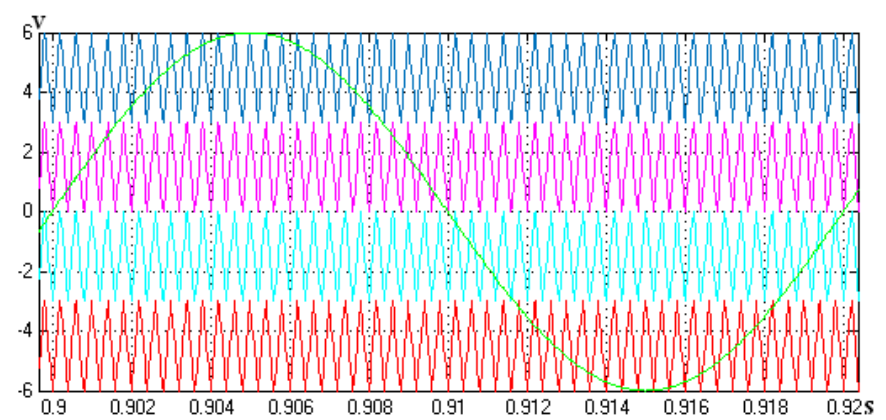

Fig. 2. The reference signal with four saw tooth carriers.

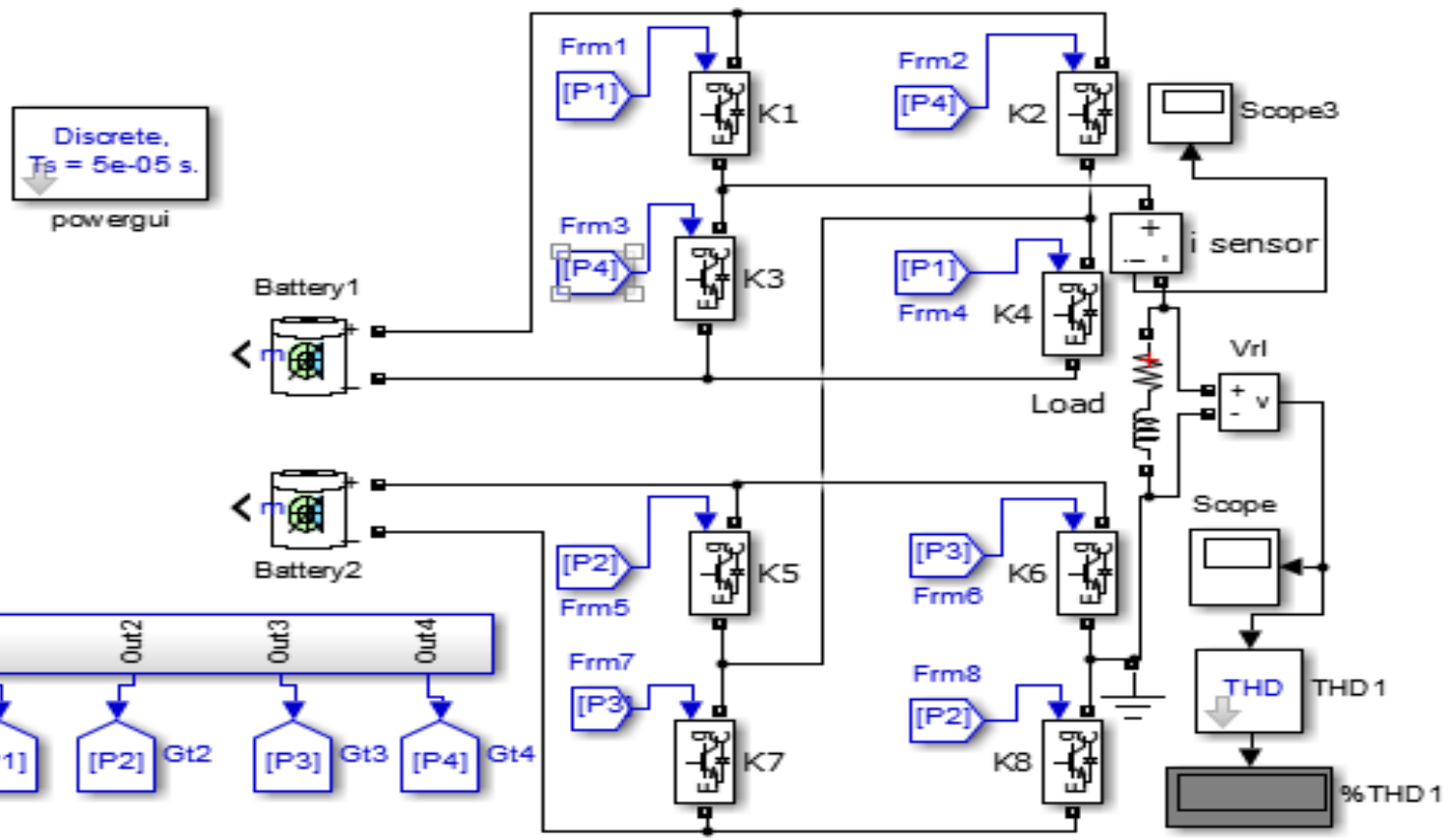

Fig. 3. CHMLI model implemented on Matlab simulink. 


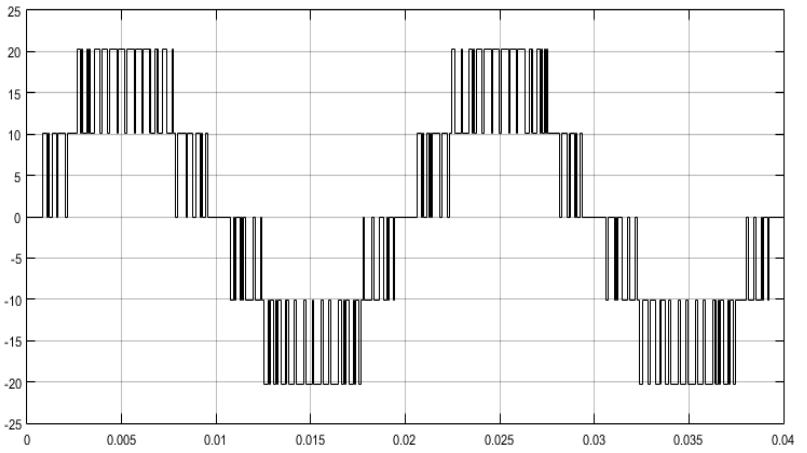

Fig. 4. Voltage output of the 5 levels cascaded H-Bridge multilevel inverter.

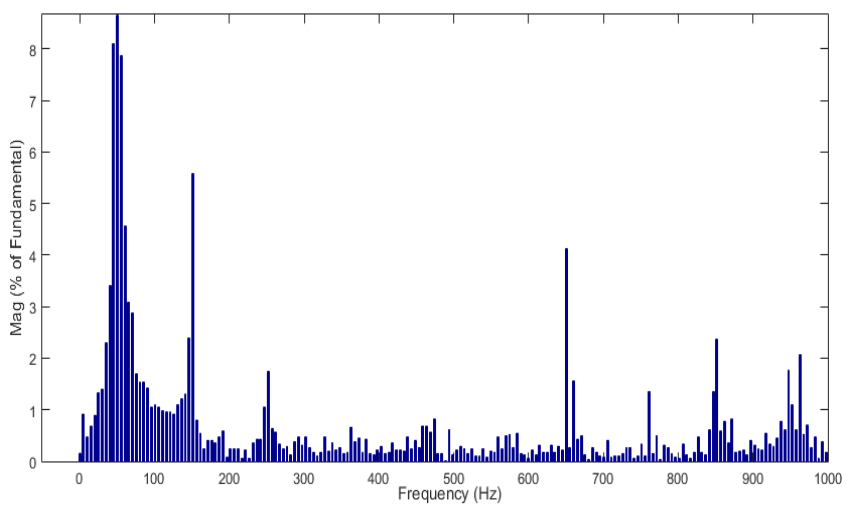

Fig. 5. Output voltage spectrum analysis of the 5 levels CHMLI.

The used load throughout the study is $(R=50 \Omega, L=$ $100 \mathrm{mH})$. Fig. 4 presents the output voltage of the CHMLI before any balancing procedure.

In order to assess the voltage output quality we conducted a signal analysis. Fig. 5 presents the voltage spectrum analysis; we registered a $32.14 \%$ THD.

\section{BATTERIES BALANCING USING A UNIFORM DISCHARGING APPROACH}

\section{A. Power Bank Discharging Model}

In order to study the discharging and balancing technique we simulated a power Bank out of lead acid batteries models. The characteristics of the simulated batteries were chosen to correspond to common used ones, they are as follows:

- Nominal voltage: $12 \mathrm{~V}$

- Rated capacity: 6.5Ah

- Initial state of charge: $100 \%$

- Maximum capacity: 6.77Ah

- Fully charged voltage: $13.06 \mathrm{~V}$

- Nominal discharge current: $1.3 \mathrm{~A}$

- Internal resistance: $0.02 \Omega$

A five levels H-Bridge multilevel inverter uses two full bridges inverters and needs two separate DC sources. Depending on the architecture and wiring configuration, each DC source may contain multiple batteries. The output voltage of the multilevel inverter $V_{0}$ can be written as follows:

$$
V_{0}=\sum_{i=1}^{n} v_{B_{i}}
$$

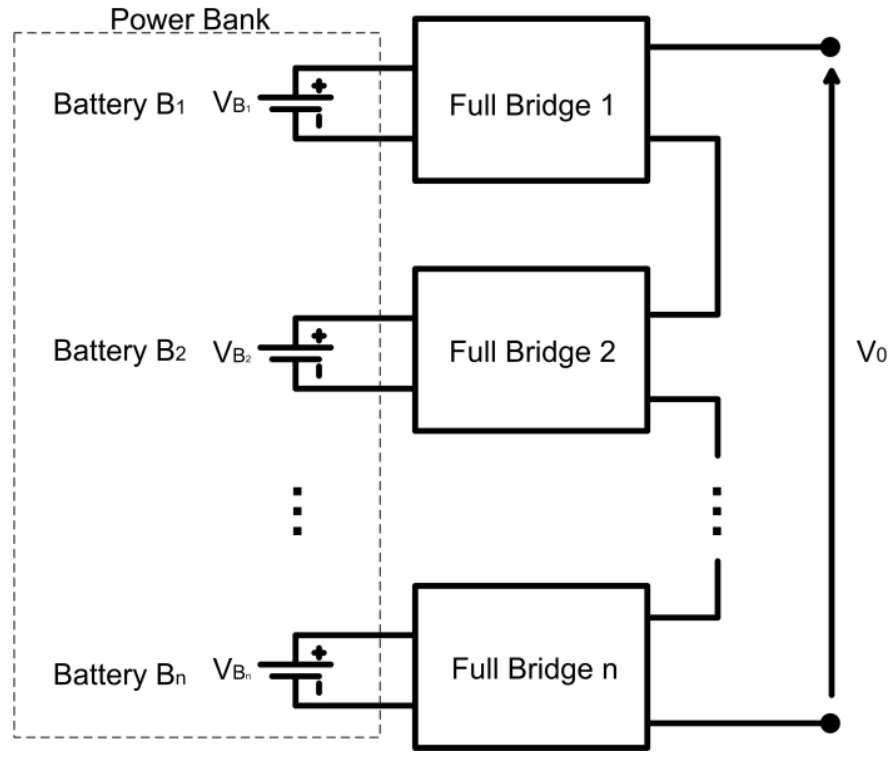

Fig. 6. $(2 \mathrm{n}+1)$ cascaded H-Bridge multilevel inverter.

Where $v_{B_{i}}$ is the voltage of the battery $B_{i}$.

Let's consider that there are $N$ batteries in the power bank and only $n$ of theme will be used where $n \leq N$. Fig. 6 illustrates how batteries can be dispatched for the use as separated DC sources for a $(2 n+1)$ H-Bridge multilevel inverter.

Order to keep a balanced discharge of the power bank's units, the batteries with the highest state of charge SOC will be triggered fist, then the $2^{\text {nd }}$ battery with highest SOC and so on until the battery with the least charge. Fig. 7 presents the principle of the algorithm managing the power bank.

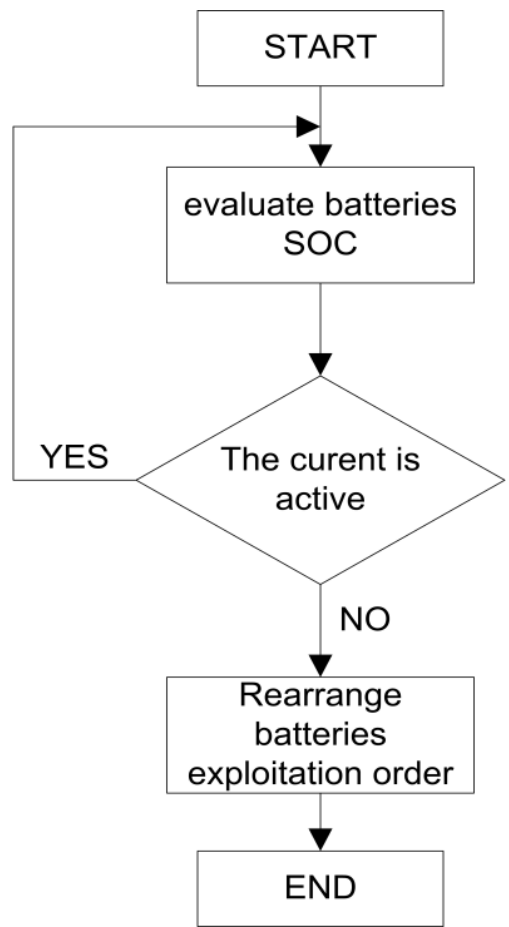

Fig. 7. Algorithm principle used for managing the Power Bank discharge. 


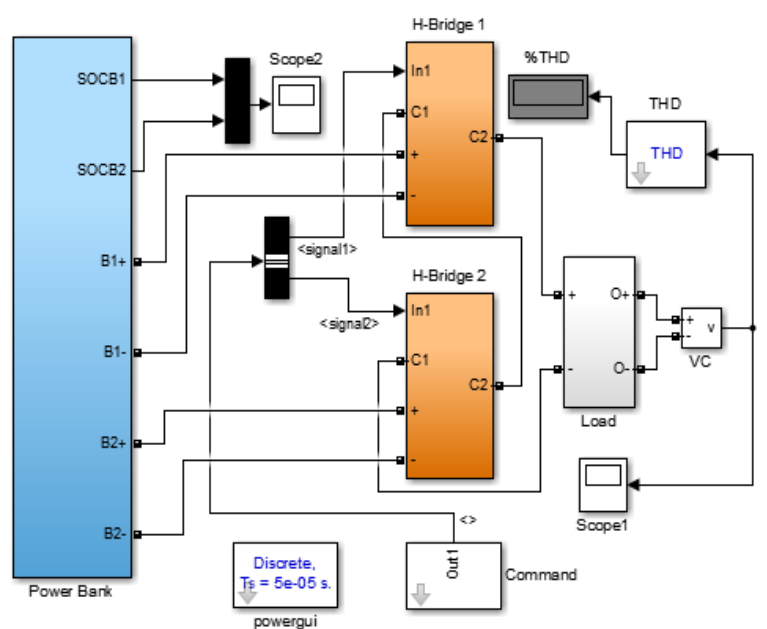

Fig. 8. Five levels Cascaded H-Bridge multilevel inverter with Power Bank.

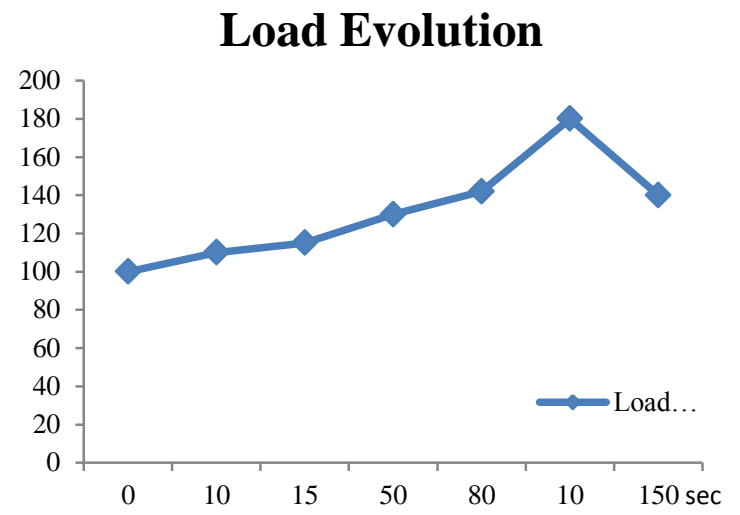

Fig. 9. Load profile applied to the multilevel inverter over time.

\section{B. Power Bank Discharge in the CHMLI}

In order to study the discharge phenomenon in the Power Bank we implemented the Matlab simulink model represented in Fig. 8.

The five levels CHMLI requires two distinct DC sources to function correctly. In this case we consider the two DC sources as two batteries having the characteristics summarized before. Thus we apply a load profile; the evolution of load trough time is illustrated in Fig. 9.

We have carefully chosen to plot a load profile with slow variation in order to assess how even a steady exploitation of the power source can affect the balance of batteries.

\section{SimUlation RESUlts AND ANALYSIS}

\section{A. State of Charge Balancing Technique}

We applied the load profile plotted in Fig. 9 to the CHMLI's output; the Power Bank contains multiple batteries but only two will be exploited simultaneously. The batteries discharge was evaluated for 150 seconds on Matlab Simulink. Fig. 10 presents the discharge approximation of the Power Bank.

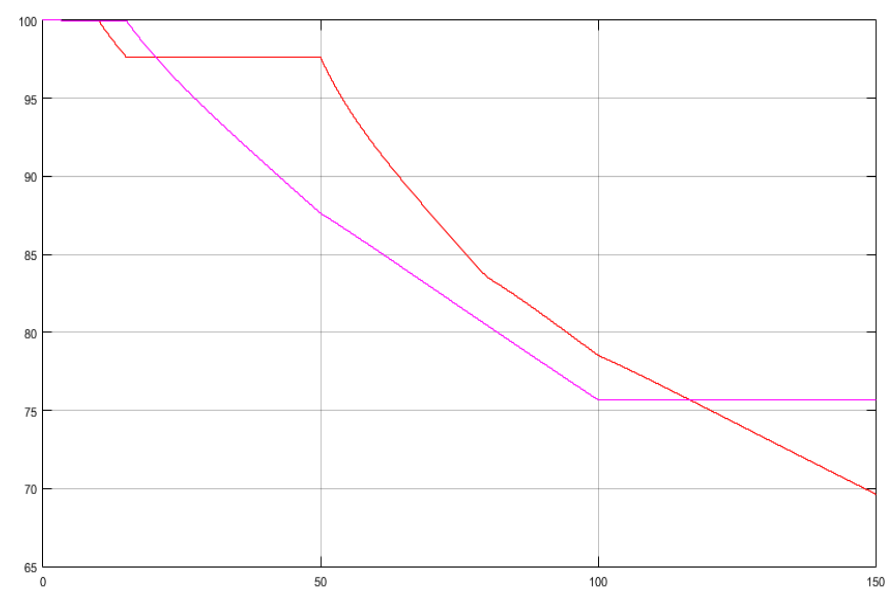

Fig. 10. Discharging profile of the two batteries inside the Power Bank.

As it can be seen in Fig. 10, the discharge of the two batteries is not equivalent which mean the state of the charge of the two batteries is not balanced; Immediately after beginning the simulation the batteries state of charge is slightly different. After the first 50 seconds of simulation the state of charge of the two batteries is at its highest difference. Because the load change within time, the difference between batteries state of charge is never steady and keep changing arbitrary. The two batteries start both at 100\% state of charge and at the end of the simulation time the first battery shows a $68.56 \%$ SOC, while the second battery has only $74.45 \%$ left. Fig. 11 presents the FFT analysis of the five levels CHMLI at the beginning of the simulation and Fig. 12 shows the FFT analysis of the same output signal with the new state of charges unbalancing at the end of the simulation.

As it can be clearly noticed in Fig. 11 and 12 the output voltage quality decreases as the state of charge of the batteries grows different due to the unbalanced state of the power bank. The THD of the voltage output at the beginning of the simulation is $35.64 \%$, while at the end of the simulation after 150 seconds simulation time the THD is evaluated at $44.56 \%$.

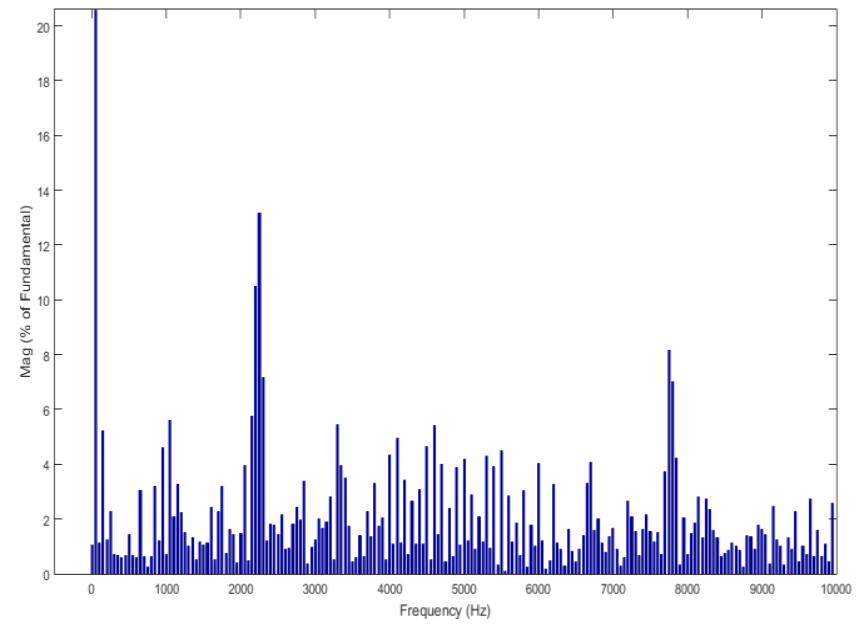

Fig. 11. FFT analysis of the output signal at the beginning of the simulation. 


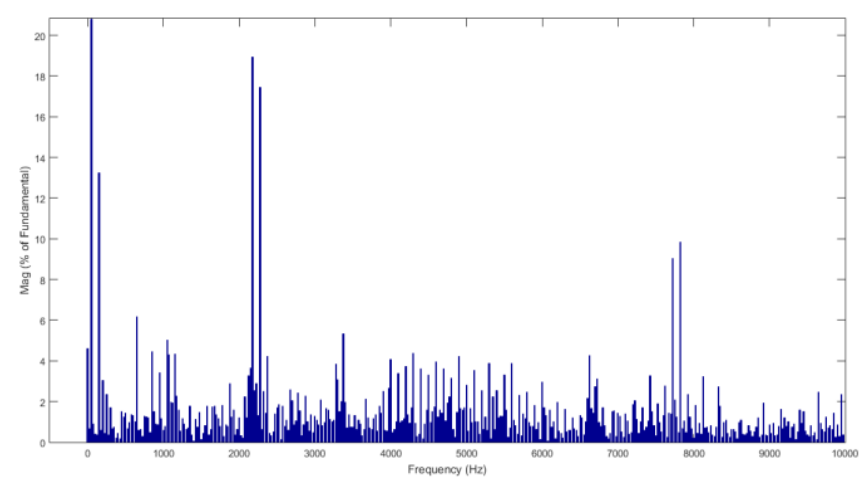

Fig. 12. FFT analysis of the output signal at the end of simulation time.

\section{B. Balancing of the 5 Levels CHMLI}

Due to the distress effect caused by the unbalanced batteries, we intend in this section to propose an appropriate balancing technique for the studied five levels CHMLI. Balancing the batteries inside the power bank can also help preventing equally the batteries from fast aging and deep discharge, and help keep a supervised equal DC sources. Fig. 12 presents the balancing algorithm used to equilibrate the power bank batteries.

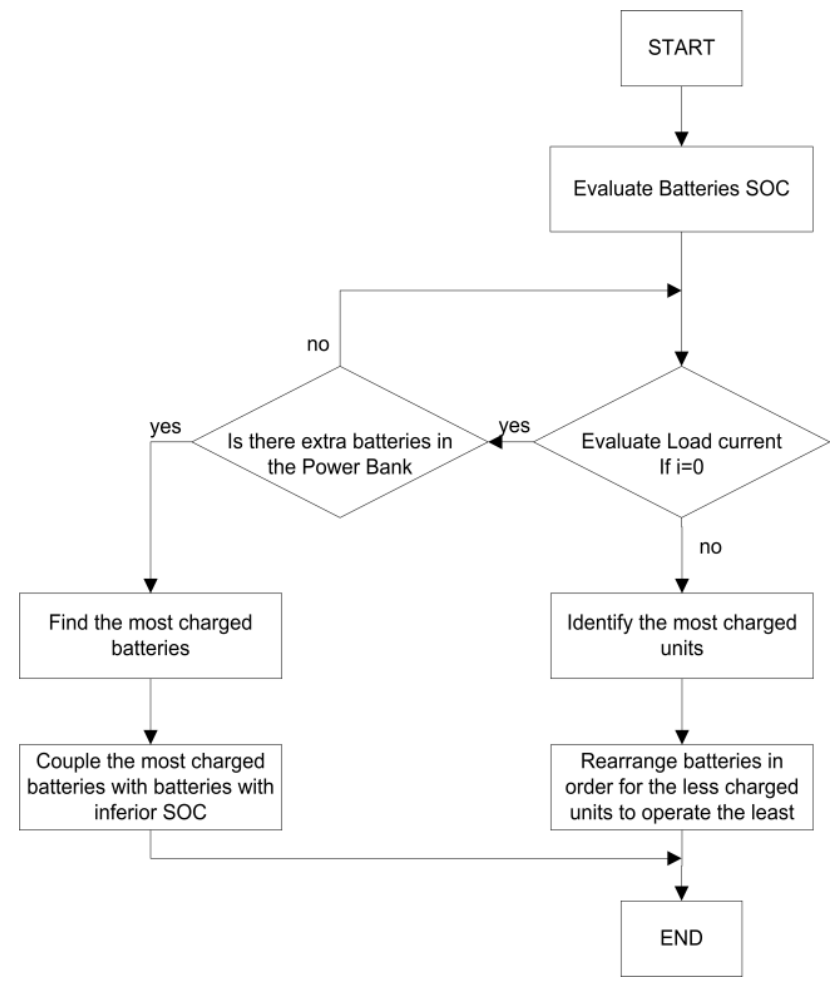

Fig. 13. Balancing algorithm used for the five levels CHMLI Power Bank.

The proposed method starts by evaluating the batteries state of charge, and then the load is checked to see if there is a current in flow. The algorithm decides whether to switch batteries positions or to use extra existing batteries to equilibrate the need for extra voltage. Fig. 13 presents the voltage evolution during balancing process for two initially different batteries.

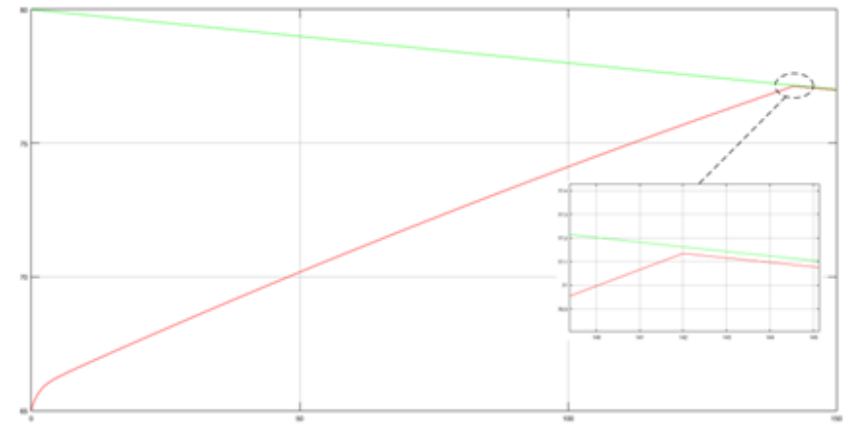

Fig. 14. SOC balance using the proposed algorithm for two initially different batteries with steady load.

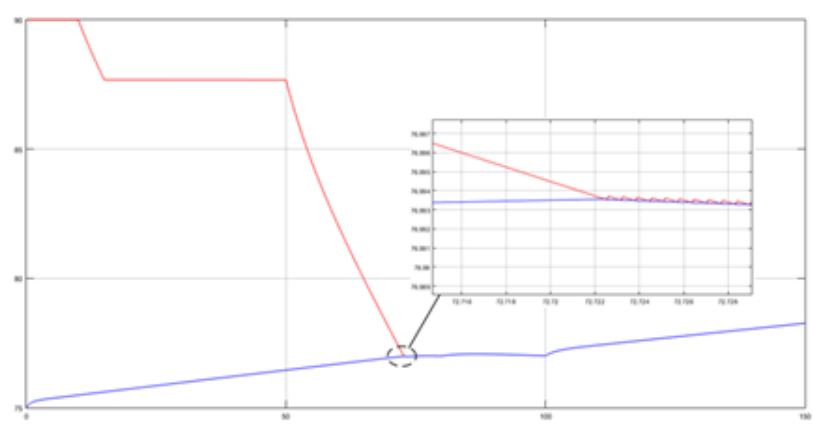

Fig. 15. Power bank balancing response to a load profile evolution over time.

We notice in Fig. 14 that the multilevel inverter uses the batteries energy in a way to equilibrate their state of charge during exploitation. Batteries state of charge is different at the beginning of the simulation; battery 1 is at $80 \%$ and battery 2 is at $65 \%$. Through the evolution of the simulation the difference between the states of charges gets minimized. This technique helps keeping the batteries at the same charge level, preserve theme from deep discharge and fast deterioration. In order to assess the power bank response to a load variation over time; we applied the same load profile presented in Fig. 9 to the power bank. The two batteries in this case are successively at $90 \%$ and $75 \%$ at the beginning of the simulation.

We clearly notice in Fig. 15 how the algorithm affects the power bank. It keeps the SOC of the two batteries close to each other as much as possible. Thus the system uses any extra batteries inside the power bank and connects it to the battery requiring voltage the most.

\section{CONCLUSION}

In this article we analyzed a five levels cascaded H-Bridge multilevel inverter. First we presented the model and command rules used in the present study. Then we presented the discharge phenomenon in the power bank model used with the multilevel inverter. The power bank was modeled out of two lead acid batteries. We studied the discharge impact on the system by applying a steady load then a load variation over time. Without the balancing algorithm the batteries are discharging in an unbalanced way; this affects the signal quality and may cause the deterioration of power storage units. 
The study has also shown that the output signal's quality decreases as the power bank grows more unbalanced. After applying the power bank balancing algorithm the batteries kept almost a similar state of charge and much good improvement was noticed on the THD. Batteries' balancing is a very important issue within renewable energy field. Further efforts aim to test the algorithm's performance and limitation when the CHMLI is functioning at high levels configuration.

\section{REFERENCES}

[1] Colak, I., Kabalci, E., \& Bayindir, R. (2011). Review of multilevel voltage source inverter topologies and control schemes. Energy Conversion and Management, 52(2), 1114-1128.

[2] Panagis, P., Stergiopoulos, F., Marabeas, P., \& Manias, S. (2008, June). Comparison of state of the art multilevel inverters. In Power Electronics Specialists Conference, 2008. PESC 2008. IEEE (pp. 4296-4301). IEEE.

[3] Khalili, T., Raihani, A., Ouajji, H., Bouattane, O., \& Amri, F. (2015). Efficient Choice of a Multilevel Inverter for Integration on a Hybrid Wind-Solar Power Station. Journal of Power and Energy Engineering, 3(09), 44.

[4] Sastry, J., Bakas, P., Kim, H., Wang, L., \& Marinopoulos, A. (2014). Evaluation of cascaded H-bridge inverter for utility-scale photovoltaic systems. Renewable Energy, 69, 208-218.

[5] Kannan, C., Mohanty, N. K., \& Selvarasu, R. (2017). A new topology for cascaded H-bridge multilevel inverter with PI and Fuzzy control. Energy Procedia, 117, 917-926.

[6] Khalili, T., Raihani, A., Bouattan, O., Ouajji, H., \& Amri, F. (2016). ANALYSIS STUDY OF A CASCADED H-BRIDGE MULTI-LEVEL INVERTER DEDICATED TO POWER BANK USAGE. Journal of Theoretical and Applied Information Technology, 88(3), 434.
[7] Tolbert, L. M., Peng, F. Z., \& Habetler, T. G. (1999). Multilevel converters for large electric drives. IEEE Transactions on Industry Applications, 35(1), 36-44.

[8] Sahoo, S. K., \& Bhattacharya, T. (2018). Phase-Shifted Carrier-Based Synchronized Sinusoidal PWM Techniques for a Cascaded H-Bridge Multilevel Inverter. IEEE Transactions on Power Electronics, 33(1), 513524.

[9] Prabaharan, N., \& Palanisamy, K. (2017). Analysis of cascaded H-bridge multilevel inverter configuration with double level circuit. IET Power Electronics.

[10] Villanueva, E., Correa, P., Rodríguez, J., \& Pacas, M. (2009). Control of a single-phase cascaded H-bridge multilevel inverter for grid-connected photovoltaic systems. IEEE Transactions on Industrial Electronics, 56(11), 4399-4406.

[11] Wei, S., Wu, B., Li, F., \& Sun, X. (2003, February). Control method for cascaded H-bridge multilevel inverter with faulty power cells. In Applied Power Electronics Conference and Exposition, 2003. APEC'03. Eighteenth Annual IEEE (Vol. 1, pp. 261-267). IEEE.

[12] Wang, L., Zhang, D., Wang, Y., Wu, B., \& Athab, H. S. (2016). Power and voltage balance control of a novel three-phase solid-state transformer using multilevel cascaded $\mathrm{H}$-bridge inverters for microgrid applications. IEEE Transactions on Power Electronics, 31(4), 3289-3301.

[13] Gholizad, A., \& Farsadi, M. (2016). A Novel State-of-Charge Balancing Method Using Improved Staircase Modulation of Multilevel Inverters. IEEE Transactions on Industrial Electronics, 63(10), 6107-6114.

[14] Li, C., Coelho, E. A. A., Dragicevic, T., Guerrero, J. M., \& Vasquez, J. C. (2017). Multiagent-based distributed state of charge balancing control for distributed energy storage units in AC microgrids. IEEE Transactions on Industry Applications, 53(3), 2369-2381.

[15] Morstyn, T., Momayyezan, M., Hredzak, B., \& Agelidis, V. G. (2016). Distributed Control for State-of-Charge Balancing Between the Modules of a Reconfigurable Battery Energy Storage System. IEEE Transactions on Power Electronics, 31(11), 7986-799 